\section{Intencionalidade e evidência em Heidegger}

\author{
Marcos Aurélio Fernandes
} Professor -adjunto - UnB ${ }^{1}$

Resumo: o presente artigo visa expor a fenomenologia da evidência no pensamento de Heidegger. Toma-se como ponto de partida e fio condutor a intencionalidade. $O$ conhecer é um relacionamento intencional que pode apresentar diversos graus de plenitude intuitiva. O grau mais pleno é o da percepção. Com o perceber se dá o preenchimento das intenções vazias e se realiza o ato de identificação: a coincidência entre o presumido e o intuído. Evidência é o ato de identificação que se clareia a si mesmo. Não é um sentimento de uma consciência fechada em si mesma. O clarear da evidência pressupõe a abertura da clareira do ser na qual o homem demora como ser-no-mundo.

Palavras-chave: intencionalidade, plenitude intuitiva, identificação, evidência, ser-no-mundo.

\author{
Intentionality and evidence by \\ Heidegger
}

\begin{abstract}
: this article aims to explain the phenomenology of evidence in Heidegger's thought. It takes as a starting point and guideline the intentionality. Knowledge is an intentional relationship, which may show various degrees of intuitive fullness. The fullest degree is that of perception. With perception occurs the filling of the empty intentions and performs the act of identification: the coincidence between the presumed and intuited. Evidence is the act of identification that clarifies himself. It is not a feeling of a closed consciousness. The clarification of evidence presupposes the open-ness of the lighting-process of Being, in which the human being establishes dwelling as a being, which exists in the mode of to-be-in-the-World.
\end{abstract}

Keywords: intentionality, intuitive fullness, identification, evidence, to-be-in-the-world. 
A presente reflexão visa expor em que consiste a natureza da evidência considerandoa desde a perspectiva da intencionalidade. Fio condutor de sua exposição é o ensinamento de Heidegger ministrado na preleção do semestre de verão de 1925, intitulada "Prolegômenos para a bistória do conceito de tempo" (HEIDEGGER, 1994a), embora também se procurará recorrer também a outros textos de Heidegger e mesmo de Husserl.

Comecemos, no entanto, perguntando: qual a relevância do tema da evidência para a fenomenologia?

A fenomenologia enquanto conceito de método, ou seja, o modo de ser da investigação fenomenológica tem como máxima a chamada: "às coisas mesmas! " [zu den Sache selbst.]. Esta máxima se opõe as palavras vazias, a conceitos só aparentemente verificados, a juízos cegos, a argumentos genéricos, a pseudoproblemas, a construções teóricas soltas no ar (HUSSERL, 1993a:. 155; HEIDEGGER, 1986: 27). Nela, o que está em jogo é a chamada para um retorno. Retornar às coisas mesmas quer dizer não se contentar com palavras vazias, mas buscar aquilo que as suas significações intencionam e, neste sentido, desdobrar intuições para chegar à evidência (HUSSERL, 1993b: 5-6). Com outras palavras, dito positivamente, esta máxima quer dizer: em investigando, ater-se ao fenômeno, ou seja, ao que vem à luz, isto é, à claridade, mostrando-se a si mesmo, tornando-se manifesto, revelando-se (HEIDEGGER, 1986: 28). Na perspectiva da exposição e da comunicação, isto quer dizer: que a fala, o discurso, há de tornar manifesto aquilo de que discorre. Ele há de deixar ver aquilo que está em causa; há de tornar acessível aquilo que está em questão, ou seja, o discurso que vem à fala deve ser haurido a partir daquilo mesmo de que se discorre (HEIDEGGER, 1986: 32). Enfim, como conceito de método, fenomenologia quer dizer: deixar ver desde ele mesmo, aquilo que se mostra, tal como se mostra a partir dele mesmo (HEIDEGGER, 1986: 34). Alguém poderia objetar que tal máxima impõe um princípio metódico óbvio a uma investigação que pretende alcançar um conhecimento científico rigoroso. De fato, este princípio metódico é óbvio. Neste sentido, o que uma investigação fenomenológica tem de novo não é o princípio que a guia, mas o pretender tomar a sério este princípio (HEIDEGGER, 1986: 28).

A máxima da investigação fenomenológica tem, pois, como "princípio dos principios": "que toda visão originariamente doadora é uma fonte justa do conhecimento; que tudo aquilo que se nos oferece originariamente numa "intuição" (por assim dizer em sua realidade em carne e osso), há de ser tomado simplesmente como aquilo que se mostra, mas também só nos limites em que se dá aî" (HUSSERL, 1993d: 43-44). Intuição quer dizer, aqui, visão originariamente doadora, simples apreensão da coisa mesma, ou seja, da coisa em causa, tal como ela se deixa encontrar previamente, tal como ela se mostra, dando-se por assim dizer "corporalmente" [leibhaftig], ou seja, não apenas simbolicamente, 
figurativamente, mas "em carne e osso", "em pessoa” (HEIDEGGER, 1994a: 64). A intuição é fonte justa de conhecimento. O conhecer é um relacionamento intencional, isto é, ele se dirige a alguma coisa. A questão é: a que se dirige o comportamento ou relacionamento intencional cognitivo? Resposta: dirige-se à coisa mesma, tal como ela se mostra e se doa por assim dizer em "carne e osso", e não a conteúdos da consciência, a sensações ou a imagens mentais. Conhecer é, deste modo, co-nascer com a coisa mesma em questão, é receber a sua doação originária, é tomar em consideração aquilo que assim é visto (HEIDEGGER, 1995: 100-101). O princípio dos princípios pode ser chamado de princípio da evidência. Ele não é propriamente uma proposição teórica, algo assim como um axioma. Trata-se de um princípio que jaz previamente a todos os princípios, isto é, que vem antes de todos princípios teóricos, por reger toda a investigação científica, e que vem antes de todos os princípios práticos, por reger a vida de uma humanidade que pretende viver na verdade e na autenticidade (HUSSERL, 1962: 299).

Feita esta reflexão preliminar sobre a relevância da evidência para a fenomenologia, tentemos expor a conexão entre evidência e intencionalidade, que é o propósito desta contribuição de pensamento.

O comportamento ou relacionamento intencional do conhecer com o cognoscível pode se dar em diversos graus de plenitude intuitiva. $\mathrm{Na}$ intenção pensante ou conhecedora e no seu modo de propor [vorstellen] para si a coisa que há de ser conhecida, com efeito, há uma gradação da completude ou plenitude intuitiva das estruturas intencionais dos diversos atos de apreensão em que o ato de conhecer ou pensar se funda. Do mais vazio para mais pleno temos: o intencionar vazio, a simples presentificação, a imagem, e a percepscão (HEIDEGGER, 1994a: 59).

O intencionar vazio [Leermeinen] é o "pensar sem pensamentos", ou seja, o pensar abreviado e cego. É o mero pensar em algo, sem considerar suas determinações. É vazio, na medida em que o pensar e falar da coisa é desprovido de intuição. O intencionado, ou seja, o pensado deste pensar vazio, é o ente mesmo, só que no modo vazio, isto é, sem a plenitude da intuição.

Em segundo lugar, vem a simples presentificação [schlichte Vergegenwärtigung]. É o pensar em algo, considerando suas determinações. Assim, uma proposição como "1 +2 é igual a $2+1$ " pode ser pronunciada às cegas, sem pensar, isto é, no modo do intencionar vazio, ou pode, por outro lado, ser dita de modo que, a cada passo, se faça uma presentificação [Vergegenwärtigung] do que nela é visado [Gemeinte]. Neste caso, se discorro sobre esta expressão, este falar não é um falar vazio, mas a intenção signitiva se torna mais plena, graças ao ato intuitivo, isto é, apreensivo e interpretativo, da presentificação. O que importa é como a proposição é enunciada, ou seja, como é executado ou realizado [vollzogen] o intencionar do juízo: se é executado sem pensar, sem evidência, ou se é realizado de modo a ver, a ter evidência do que se trata a cada passo, isto quer dizer, se cada determinação da proposição é presente ao que julga em seu significado originário, por meio de uma originária, intuitiva, presentificação. $\mathrm{O}$ intencionado do simples presentificar é o ente mesmo, não uma imagem dele. $\mathrm{O}$

Revista de Filosofia Moderna e Contemporânea

Brasília, vol 3, no 2, 2015. 
modo como ele é apreendido, quer dizer, interpretado, consiste em se mostrar ao pensamento em diversos aspectos e perspectivas (HEIDEGGER, 1994a: 55). Assim, por exemplo, se estou em Belo Horizonte e penso no aeroporto de Confins, considerando os seus aspectos, sob diversas perspectivas, então eu realizo um ato de simples presentificação, que é diverso, tanto do ato de recordar, como do ato de imaginar o aeroporto de Confins. Isto quer dizer: quando presentifico alguma coisa eu estou junto desta coisa mesma. A presentificação tem o caráter do ser-junto-a [den Charakter des Seins bei...]; no caso, do meu ser junto ao aeroporto de Confins. Estando em Belo Horizonte, tenho em mente, viso, o aeroporto de Confins. E, tendo-o em mente, visando-o, estou junto a ele. Se, por exemplo, devo pegar uma condução do transporte público ou se devo dirigir um carro para chegar ao aeroporto de Confins, isto só é possível, por que, tendo-o em mente, visando-o, já estou junto a ele. Este pensar-em é, pois, mais do que um simples recordar; é, em visando, um estar-junto da coisa mesma que é visada. Este ser-junto-ao-ente da simples presentificação apresenta, pois, o caráter de um estar-aberto [Offenstehen] para o ente em sua vigência. Neste sentido, em visando o aeroporto de Confins, estou junto a ele, enquanto um carro estacionado no aeroporto de Confins, que não o pode visar, não (HEIDEGGER, 1987: 86-96).

Em terceiro lugar, vem a presentificação que se dá na percepşão de imagem [Bildwahrnehmung]. Esta apreensão, em seu grau de plenitude intuitiva, está a meio caminho, entre a simples presentificação e a simples percepção. Digamos que eu, estando na Universidade, tenha em mãos um livro de fotografias da Igreja de São Francisco, que está na Pampulha. Por meio desta coisa- imagem [Bildding], eu posso conhecer algo da sua arte, isto é, da sua arquitetura, obra de Niemeyer, bem como da sua arte visual, isto é, da obra de Portinari. O visado, o intencionado, neste ato apreensivo é o ente mesmo, no caso, o que é retratado [das Abgebildete] por meio da coisa-imagem, ou seja, no nosso exemplo, é a Igreja de São Francisco da Pampulha retratada por meio do livro de fotografias. Temos, então, uma presentificação do ente mesmo em questão, mas não em carne e osso. Bem outra coisa é se vou à Pampulha e visito a Igreja de São Francisco da Pampulha e contemplo a sua arte. A consciência perceptiva de alguma coisa é, com efeito, bem diversa, em sua estrutura, da consciência da imagem. Naquela eu vejo a coisa mesma, diretamente, em carne e osso. Nesta eu vejo o que é retratado por meio de uma coisa-imagem. A evidência de uma coisa retrata e a evidência de uma coisa percebida diretamente, em carne e osso, têm uma pregnância intuitiva diversa. Assim, se falo da arte da Igreja de São Francisco, que está na Pampulha, apenas por ter ouvido falar dela, ou apenas por ter visto um livro de fotografias dela, e se falo dela por ter estado lá, por tê-la tido presente em carne e osso, este falar e discorrer sobre ela tem uma plenitude intuitiva cada vez diversa (HEIDEGGER, 1994a: 55-57).

Em quarto lugar, vem a simples e originária percepção [Wabrnebmung]. O que nela acontece não é um presentificar [Vergegenwärtigen], mas é, mais do que isto, um tornar presente [Gegenwärtigen], um presentar [Präsentieren] a coisa mesma, tal como ela se dá em carne e osso [leibhaftig] (HUSSERL, 1993c: 116). O intencionado do simples perceber é a coisa mesma em sua doação em carne e osso. Assim, se apreendo um ipê amarelo florido, o visado da minha 
percepção é o próprio ipê amarelo florido, e não uma imagem ou uma representação deste ipê amarelo florido na minha consciência. $\mathrm{O}$ visado é, pois, o próprio ipê amarelo florido, dando-se em carne o osso. O perceber é, então, um simples apreender, um simples ver [schlichtes Sehen], e o percebido é aquilo que é simplesmente visto [das Schlichtgesehene]. A perceptibilidade [Wahrgenomenheit] do percebido tem o caráter de uma doação em carne e osso [leibhaftig]. O caráter de ser doado em carne e osso [Leibhafigkeit] é um modo privilegiado de autodatidade [Selbstgegebenheit] do ente percebido (HEIDEGGER, 1994a: 54). Aqui a plenitude intuitiva do ato de apreensão chega ao seu máximo. Em sentido estrito, ou melhor, pleno e pregnante, há intuição toda vez que a coisa intencionada no comportamento se dá como sendo presente em carne e osso [leibhaftig anwesend] (HEIDEGGER, 1995: 103). Como já dissemos, na percepção se dá não uma mera presentificação, mas sim uma presentação da coisa mesma. No entanto no caso de uma percepção sensível de uma coisa material, "por mais adequada que possa ser uma percepção, o ente percebido se mostra sempre cada vez somente em um determinado sombreamento [Abschattung]" (HEIDEGGER, 1994a: 65). Em vez de sombreamento, podemos dizer também "nuança". No caso da percepção sensível de uma coisa material, o visado do perceber é sempre a coisa mesma em sua totalidade, mas o que eu apreendo é sempre esta coisa desde determinada perspectiva e sob um determinado aspecto. Eu vejo, por exemplo, a parte superior da cadeira, enquanto não consigo ver a superfície inferior. Todavia, não penso, por isso, que as pernas da cadeira foram serradas, porque, no meu perceber, naturalmente conto com o mostrar-se nuançado das coisas percebidas. Num movimento em torno da coisa, os aspectos que vêm à luz de modo nuançado podem mudar, no entanto, no perceber e com o perceber acontece também a consciência de que este percebido é o mesmo ente, a mesma coisa. Esta consciência da "idemidade" [Selbigkeit] do percebido faz parte do ato de perceber. Aspectividade, nuança e idemidade são traços caraterísticos da perceptibilidade de uma coisa material apreendida por uma percepção sensível (ROMBACH, 1980: 171-191).

Os atos signitivos vazios se preenchem com a plenitude intuitiva da percepção. No perceber, em virtude de sua presentificação intuitiva, se dá, pois, o preenchimento [Erfüllung] dos atos signitivos vazios. A presentificação intuitiva, por assim dizer, faz acontecer o cumprimento [Erfüllung] de um presumir [Vermeinen], isto é, aquilo que era presumido se cumpre, à medida que o ato de apreender encontra o ente doandose em seu teor intuitivo. O presumir, então, se cumpre, à medida que se funda e se legitima no que intuitivamente se documenta, isto é, se mostra partir de si mesmo [weist aus] como sendo a coisa mesma visada e presumida. "A percepção, assim como o que ela dá, se mostra [weist aus]. A intenção vazia se documenta no estado-de-coisas dado na intuição; a percepção originária dá a auto-mostração da coisa mesma [Ausweisung]" (HEIDEGGER, 1994a: 66).

Por meio da percepção, ou melhor, por meio de sua auto-mostração, o presumido encontra cumprimento no intuído, ou seja, o presumido coincide com o intuído. Por exemplo, vamos supor que eu presuma que a Igreja da Pampulha seja bela. E, ao visitála, ao tê-la presente [Gegenwärtig haben] em seu teor intuitivo, a percepção me mostre a ela

Revista de Filosofia Moderna e Contemporânea

Brasília, vol 3, no 2, 2015. 
mesma dando-se em sua beleza. Se antes eu dizia: "A Igreja de São Francisco da Pampulha deve ser bela" e agora eu digo "A Igreja de São Francisco da Pampulha é realmente bela", neste caso, uma expectativa encontrou um cumprimento [Erfüllung]. O juízo "A Igreja de São Francisco da Pampulha é bela" se documenta, se prova, se confirma, com o intuído na percepção. $O$ presumido é trazido à coincidência com o intuído. Isto quer dizer: experimentar o presumido no intuído enquanto ele mesmo [es selbst] e como o mesmo [selbiges]. Este trazer à coincidência é o que se denomina de ato de identificação [Akt der Identifizierung]. Nesta identificação, a idemidade [Selbigkeit] é experimentada, o que não significa que ela é apreendida explicita e tematicamente como idemidade. Isto quer dizer também que o ato de identificação não é ainda apreensão da identidade, mas apenas apreensão do idêntico. $\mathrm{O}$ ato de identificação é a experiência de que o presumido se funda na coisa mesma, no que ela mostra de si, a partir de si, isto é, de sua realidade efetiva, de sua presença doada em carne e osso. "Neste preenchimento enquanto um ato de identificação jaz uma tomada de intelecção [Einsichtnabme] do ser-fundado na coisa mesma do presumido, e esta tomada de intelecção enquanto preenchimento identificador se designa como evidência" (HEIDEGGER, 1994a: 67).

$\mathrm{Na}$ preleção do semestre marburguense de inverno de 1925/1926 sobre a "Lógica: a pergunta pela verdade", Heidegger retoma o que foi exposto na preleção no semestre de verão de 1925, intitulada "Prolegômenos para a bistória do conceito de tempo", acerca da evidência. Mas esta retomada deixa mais nítida, na apreensão ou interpretação do modo de ser da evidência, a dinâmica da intencionalidade. Vejamos.

Nas intuições há diversos modos e graus e níveis de plenificaşão [Erfüllung]. Esta, por sua vez, a plenificação, pode ser tomada em dois sentidos. Primeiro, como dar plenitude: o pleno. Segundo, como dar plenitude: como confirmar, comprovar [Bewähren]. O representar vazio carece de plenificação e tem a tendência para a comprovação fundada na auto-mostração [Ausweisung]. Esta tendência, em sua intencionalidade, tem em si a direção para o campo, que, intuído, oferece plenificação. Mas, o que significa comprovação fundada na auto-mostração [Ausweisung]? Significa o seguinte: o intencionado no representar vazio é trazido, assim como ele é visado, diante do mesmo que ele intenciona. Assim, o representar muda o seu modo de se ater ao ente mesmo: de uma atinência vazia a uma atinência plena, isto é, a um relacionamento que se atém à presença em carne e osso do ente mesmo. A representação vazia se documenta, se comprova, se legitima em referência à coisa de modo a identificar-se com ela, ou melhor, de modo a identificar aquilo que ela intenciona com a coisa, mais precisamente, com a coisa enquanto ela mesma e enquanto esta mesma coisa [als sie selbst und dieselbe] (HEIDEGGER, 1995: 106).

Na comprovação, aquilo que é representado de modo vazio e aquilo que é intuído são trazidos à coincidência [zur Deckung]. Este vir à coincidência é uma questão de intencionalidade. A comprovação a partir da auto-mostração da coisa mesma se realiza de modo intencional, isto é, como um dirigir-se a [Sich-richten-auf]. Isto quer dizer: o intencional representar vazio, na tendência para a plenificação, se comprova e vive ele mesmo na identificação. Enquanto intencional, a representação vazia, dando 
prova de si mesma, sabe de si mesma, sabe que ela se auto-mostra, se documenta e se legitima. A realização intencional da identificação traz consigo a mirada intelectiva [Einblick] para dentro da automostração documentadora e comprovadora [Ausweisung]. Esta não é algo que se cola à representação vazia, mas é um modo de sua execução, ou seja, de sua realização ou consumação [Vollz̧ug] (HEIDEGGER, 1995: 107).

A intuição não se perde na coisa intuída $\mathrm{e}$ no seu conteúdo objetivo. O conhecimento, enquanto apreensão intuitiva, vive não somente junto do que ele conhece. $\mathrm{O}$ conhecimento vive junto de si mesmo. É, por assim, dizer, conhecimento de ser conhecimento e de ser conhecimento correto. Sua correção [Rechtmässigkeit], porém, é o caráter de poder ser provado $e$ documentado a partir de uma auto-mostração [Ausweisbarkeit] e, respectivamente, o caráter de ter sido provado e documentado junto à coisa [Augewiesenheit an der Sache]. A identificação, a prova, é uma questão de intencionalidade. Em sua realização intencional, sem uma reflexão própria, a identificação, respectivamente, a prova, cumpre um esclarecimento [Aufklärung] sobre si mesma. Este autoesclarecimento que se dá na realização da identificação mesma, sem precisar recorrer a uma compreensão reflexiva própria, pode ser chamado de evidência (HEIDEGGER, 1995: 107-108). E então vem a definição de evidência:

Evidência é o ato de identificação [Identifizierung] que se compreende a si mesmo como tal; o compreender-se é dado com o ato mesmo, porque o sentido intencional do ato intenciona algo de idêntico enquanto idêntico [etwas Selbiges als Selbiges] e, com isto, com o seu intencionar, eo ipso se clareia [erhellt] a si mesmo (HEIDEGGER, 1995: 108).

Evidência é, assim, autoclarificação e autocompreensão do ato de identificação, ou melhor, de sua captação identificadora. Aqui se dá, de antemão, a imediata unidade de nóesis-e-nóema, ou seja, de intencionar (ato identificador) e intencionado: o percebido no seu caráter de idemidade, isto é, o idêntico enquanto idêntico. O intencionar não só visa, intenciona [meint] e capta [erfasst] o intencionado, mas, ao mesmo tempo, por si mesmo, se clareia [erhellt] a si mesmo, se esclarece [klärt sich auf] a si mesmo. E isto, operativamente, em sua própria realização, execução ou consumação [Voll:̧ug], antes de qualquer reflexão e tematização.

Evidência é, pois, um autoclareamento, um autoesclarecimento de uma intencionalidade. Evidente quer dizer manifesto [offenbar], notório [offenkundig]. Traz consigo, portanto, em primeiro lugar, o sentido de abertura [offen = aberto $], \mathrm{e}$, em segundo lugar, o de clareamento e esclarecimento [Aufklärung], e, por fim, o de dar a conhecer [kundgeben]. Em latim há o verbo "evideri", que podemos traduzir "deixar-se ver" [sich sehen lassen]; e, em grego, há o adjetivo enargés, que quer dizer "manifesto", "claramente visível", mas no sentido do que está "aparecendo de modo fulgente". Este vem da composição de ejn [en] mais argós: o que se dá no modo esplendente, luzente. Da mesma raiz de argós é a palavra latina argentum (prata). Portanto, a experiência grega que vem à fala na palavra enargés, põe em relevo a significância decisiva que a luz tem para os gregos na compreensão do ser, tomado

Revista de Filosofia Moderna e Contemporânea

Brasília, vol 3, no 2, 2015. 
enquanto um aparecer e brilhar, mais precisamente, enquanto o resplandecer de um brilho argênteo, lunar, do que "está se mostrando a partir de si mesmo" (HEIDEGGER, 1987: 5). Nessa experiência, se compertencem a physis, o emergir manifestador, o surgir, o irromper, o brotar, o abrir-se da realidade, enfim, a natureza, e phos, a luz e a claridade, ou seja, o elemento, o medium, em que alguma coisa pode se tornar manifesta, visível nela mesma (HEIDEGGER, 1986: 28). Algo dessa experiência do ser como um brilhar e resplandecer argênteo emerge nos versos de Safo: "Estrelas em torno da bela lua / escondem sempre de novo os contornos / cintilantes, / quando toda redonda brilha cheia sobre a / terra" (Apud HEIDEGGER, 1977b: 330). Algo dessa experiência ainda ressoa na seguinte sentença poética de Hölderlin: "O brilhar da natureza é uma parusia superior! " (Apud HEIDEGGER, 1977a: 334). É ainda esta experiência que está recolhida na palavra phainómenon, que quer dizer o que se põe a brilhar, o que aparece no seu próprio brilho, e, assim, se mostra, se manifesta, e, manifestando-se, se divulga, dá notícia de si, torna-se notório, evidente ( $C f$. HEIDEGGER, 2003: 104).

O método grego de pensar tinha como traço fundamental conservar e 'salvar' os fenômenos que se mostram, deixando-os intocados e incólumes, ou seja, o puro deixar-ser-vigente daquilo que se mostra (HEIDEGGER, 1987: 143). Este método aponta para uma possibilidade de pensamento para a fenomenologia, diversa do método da dúvida cartesiana, que funda a filosofia a metafísica da subjetividade moderna, e também do método científico, que põe em ato a metafísica da objetividade e da funcionalidade moderna. Tal possibilidade pode ser assim formulada: "envolver-se propriamente em nossa relação com o que se dá a encontrar" (HEIDEGGER, 1987: 143). Trata-se, aqui, daquela relação em que nós já sempre nos demoramos, a saber, a relação primordial com o ente, em que o ente é compreendido enquanto ente, quer dizer, na perspectiva do seu ser. Nós já sempre nos detemos e nos demoramos na relação com o que se nos dá a encontrar. Estamos, assim, já sempre abertos para o encontro com o ente. $\mathrm{O}$ nosso "estar-aqui" [Hier-sein] é já sempre um "ser-juntoa" [Sein-bei], a saber, junto ao ente (HEIDEGGER, 1987: 141). Este manterse aberto a e envolver-se com o que se deixa encontrar, interessando-se por e metendo-se em relação com ele, caracteriza o modo de ser do existir, próprio do humano. Existir é realizar, consumar, este relacionamento primordial. $\mathrm{O}$ homem não existe sem o relacionamento com as coisas. O ser-consciência-de, da intencionalidade, se revela, nesta perspectiva, um ser-junto-a, a saber, um ser-junto-ao-que-nos-vem-aoencontro, um ser-junto-ao-ente, relacionamento que implica sempre numa compreensão de ser deste ente, à medida que o ente é apreendido "enquanto" ente, quer dizer, na significância de ente, ou, melhor ainda, na perspectiva do ser. Como apareceu ao se tratar da intencionalidade da "simples presentificação”, o ser-junto-ao-ente apresenta o caráter de um estar-aberto [Offenstehen] para o ente em sua vigência. O "envolver-se propriamente em nossa relação com o que se dá a encontrar" (HEIDEGGER, 1987; 143), traz consigo a seguinte implicação prática à fenomenologia:

A fenomenologia pertence em certo sentido
o ato de vontade, de não se fechar contra
este envolver-se. O envolver-se também nem
de longe quer dizer meramente um tornar-
se consciente de meu modo de ser. Eu só
posso então falar de tornar-se consciente, se
eu quero tentar determinar como este nosso

Revista de Filosofia Moderna e Contemporânea

Brasília, vol 3, no 2, 2015. 
originário ser-junto-a... se conecta com outras determinações da presença [Dasein]. (HEIDEGGER, 1987;143).

A compreensão do caráter intencional da evidência - interpretando-se a intencionalidade como um ser-consciência-de e este como um meter-se em relacionamento com, e este como um ser-junto-a.. - abre a possibilidade para superar um modo de consideração da evidência que Heidegger, na preleção dos "Prolegômenos à história do conceito de tempo", chama de "mitológica" (1994a: 67), porque "não corresponde ao que ao achado" (1994a: 68). A este modo de consideração pertence, por exemplo, o "sentimento de evidência" de Rickert.

Toma-se a evidência por um indice peculiar de certas vivências, e, antes de tudo, das vivências judicativas, por um sinal, que às vezes emerge na alma e anuncia que o processo psíquico, ao qual ele aparece ligado, seja verdadeiro, em certa medida, como um anúncio de um dado psíquico, que ao julgar corresponderia fora algo de real. Este transcendente não pode, como se sabe, tornar-se ele mesmo imanente, precisa, por isso, se deixar anunciar no "interior". Isto é, segundo Rickert, o assim chamado "sentimento de evidência". (HEIDEGGER, 1994a: 67).

Assim, a evidência seria algo como um sentimento psíquico ou um dado psíquico, algo como uma pressão, ou ainda um indício que permite notar que a verdade está ali. Este modo de considerar a evidência pressupõe que a consciência seja algo como uma "cápsula" (Cfr. HEIDEGGER, 1994a: 3). Ora, se se parte da intencionalidade, não faz sentido pensar uma consciência sem a sua correferência ao mundo no seu todo, como intuiu Husserl, indo além de Descartes (HEIDEGGER, 1987: 142; cf. HUSSERL, 1950: 70). Por isso, o problema fundamental da teoria do conhecimento moderna, herança cartesiana, que pode ser assim formulado: "como poderá a evidência (a clara et distincta perceptio) reivindicar ser algo mais que um caráter de consciência para mim? "; ou, que pode ser formulado também assim: "como poderei sair da ilha da minha consciência e como poderá adquirir significação objetiva aquilo que surge na minha consciência como vivência da evidência? ", acaba revelando-se como um pseudoproblema e um contrassenso (HUSSERL, 1950: 116).

Esse modo de assim tratar a "vivência de evidência", como "sentimento de evidência", falha por não perceber que a intencionalidade é determinante em toda a "vivência de evidência". Quer dizer: ele desconhece que "evidência é um determinado ato intencional e, precisamente, a identificação de presumido e intuído; o presumido reluz ele mesmo junto à coisa" (HEIDEGGER, 1994a: 67). Ele negligencia, além disso, que intencionalidade, isto é, o caráter da consciência de serconsciência-de, significa, um dirigir-se-a, que, fundamentalmente, tem o caráter de um poder orientar-se [Zurechtfinden], e, por fim, de um estar-aberto [Offenstehen] por parte do homem para o ente em sua vigência (HEIDEGGER, 1987: 284; 94). A abertura [Offenheit] que é própria ao homem chama-se, em Ser e Tempo, "Dasein". Ela traz consigo uma remissão a espaço e espacialidade, mas isto precisa ser bem compreendido. A palavra "Dasein", que costumeiramente quer dizer présence (presença), não quer dizer um "être-lă" (ser-

Revista de Filosofia Moderna e Contemporânea

Brasília, vol 3, no 2, 2015. 
aî no sentido de uma "indicação de lugar para um ente", "mas deve nomear a abertura [Offenheit], na qual o ente pode ser presente para os homens, na qual também ele pode ser presente para si mesmo" (HEIDEGGER, 1994b: 300; 1994a: 156-157). Espacialidade não quer dizer, aqui, ocorrer dentro do mundo. Mas, antes, ser a abertura em que se dá a eclosão do mundo enquanto tal, e, a partir daí, orientar-se como ser-no-mundo. "Espacialidade pertence à clareira [Lichtung], pertence ao aberto [zum Offenen], no qual nós, como existentes, demoramos, e, precisamente, de tal modo que nós até mesmo não estamos propriamente referidos ao espaço enquanto espaço" (HEIDEGGER, 1987: 188). Estar na clareira quer dizer, aqui, nela demorando, ocupar-se com as coisas. Ser-consciente [Bewisst] quer dizer: orientar-se no mundo circundante, entre as coisas. O orientar-se é um ser-referido ao que está dado enquanto objetos (HEIDEGGER, 1987: 190). Assim, a consciência, em seu caráter intencional, pressupõe o ser-no-mundo, que é próprio do "Dasein" e do seu existir, o que pressupõe o aberto [das Offene], a clareira [Lichtung] do ser. Para o homem, existir é demorar-se [sich aufhalten] nesta clareira. Isto quer dizer que:

Existir bumano, em seu fundamento essencial, nunca é somente um objeto que ocorre em algum lugar, e, desde já, não é nenbum objeto fechado em si. Antes, consiste, este existir, de "puras e simples" possibilidades de recepção-percepção Vernehmensmöglichkeiten], não captáveis de modo óptico, tátil, direcionadas para o que se lhe dá a encontrar a modo de apelo lauf das ihm sich zusprechende Begegnende]. (HEIDEGGER, 1987: 3).
A evidência é, assim, o autoclareamento deste relacionamento do homem com o que se lhe dá a encontrar, e, assim se dando, se lhe manifesta como anúncio, como portador de uma significância, mais do que isso, como portadora de uma mensagem, enfim, de uma fala que se lhe ressoa como apelo, animação, consolação, encorajamento [Zuspruch]. Praticar fenomenologia é, pois, não se furtar ao e não se bloquear contra o relacionamento com isso que se nos dá a encontrar e que nos interpela. É, pelo contrário, envolverse neste relacionamento, e, na experiência da evidência, guardar, conservar, junto com o que se manifesta e se clareia, o que se esconde e se oculta. É, pois, na paciência, ser capaz de suportar este relacionamento. É, enfim, um corresponder que se sintoniza com a linguagem, quer dizer, com a entonação da vOz do ser do ente (da realidade do real) que percute e repercute no silêncio. ( $C f$. HEIDEGGER, 1956: 43-44).

\section{Referências bibliográficas}

HEIDEGGER, M. (1956). Was ist das - die Philosophie? Pfullingen: Günther Neske.

(1977a). A questão sobre a morada do homem (1969). Revista de Cultura Vozes, 333-334.

(1977b). Uma palavra de agradecimento (1959). Vozes, 329-331.

(1978). Frübe Schriften Gesammtausgabe Band I. Frankfurt am Main: Vittorio Klostermann. (1986). Sein und Zeit. Tübingen: Max Niemeyer. 
(1987). Zollikoner Seminare:

Protokolle - Gespräche - Briefe. Hrsg. von Medard Boss. Frankfurt am Main: Vittorio Klostermann.

- (1994a). Prolegomena zur Geschichte des Zeitbegriffs: Gesammtausgabe 20. Frankfurt am Main: Vittorio Klostermann.

Philosophie (Vom Ereigni. Gesammtausgabe Band 65. Frankfurt am Main: Vittorio Klostermann.

. (1995). Logik: die Frage nach der Wabrheit: Gesammtausgabe 21. Frankfurt am Main: Vittorio Klostermann.

(2003). A caminho da linguagem. Petrópolis-RJ: Vozes.

HUSSERL, E. (1950). Cartesianische Meditationen und Pariser Vorträge Husserliana Band I. Haag: Martinus Nijhoff.

. (1962). Pbänomenologische Psychologie (Husserliana Band X). Haag: Martinus Nijhoff.

. (1993a). Logische Untersuchungen I: Prolegomena zur reinen Logik. Tübingen: Max Niemeyer.

. (1993b). Logische Untersuchungen II/1: Untersuchungen zur Phänomenologie und Theorie der Erkenntnis. Tübingen: Max Niemeyer.

(1993c). Logische Untersuchungen II/2: Elemente einer phänomenologischen Aufklärung der Erkenntnis. Tübingen: Max Niemeyer.

Revista de Filosofia Moderna e Contemporânea

Brasília, vol 3, no 2, 2015. (1993d). Ideen zu einer reinen

Phänomenologie und phänomenologischen Philosophie. Tübingen: Max Niemeyer.

ROMBACH, H. (1980). Phänomenologie des Gegenwärtigen Bewusstseins. Freiburg i.B./ München: Alber. 